U.S. Public Health Service

1966. Vital Statistics of the United States (Mortality Rates by Race).

Vogt, Evon Z.

1955 "American subcultural continua as exemplified by the Mormons and Texans", American Anthropologist 57:1163-1173.

Wolfgang, Marvin

1958 Patterns in Criminal Homicide. Philadelphia: University of Pennsylvania Press.
Wolfgang, Marvin, with Franco Ferracuti

1967 The Subculture of Violence. London: Tavistock Publications.

Zelinsky, Wilbur

1951 "Where the South begins." Social Forces 30:172-178.

1961 "An approach to the religious geography of the United States." Annals of the Association of American Geographers 51 (2): 139-193.

\title{
THE CAUSES OF RACIAL DISTURBANCES: TESTS OF AN EXPLANATION *
}

\author{
Seymour SpILERMan \\ University of Wisconsin
}

American Sociological Review 1971, Vol. 36 (June):427-442

\begin{abstract}
The adequacy of a recently proposed explanation for the location of racial disorders during the 1960's is evaluated in this paper. Two approaches to evaluation are used: (1) The proportion of variation accounted for by the variables assumed to be related to the occurrence of disorders is compared with an estimate of the "maximum explanable proportion of variation," and (2) the structural equation derived from an analysis of the 1961-67 disorders is used to predict the locations of the 1968 disturbances. The conclusions from these investigations support the proposed explanation only with respect to the non-South, but indicate that the distribution of disorders among southern cities has been converging during the late 1960's to the pattern which has been prevalent in the non-South throughout this decade. This finding is interpreted as evidence of the decreasing importance of regional cultures as an intervening factor in the development of black solidarity.
\end{abstract}

\section{INTRODUCTION}

$\mathrm{I}$ a recent analysis of racial disturbances which occurred during the 1960's (Spilerman, 1970b), it was argued that the distribution of disorders among cities is not consistent with an explanation which locates the causes of rioting in community conditions. Communities do differ in the rate at which they have incurred racial violence during this period, yet the conclusion from the analysis was that these differences cannot be accounted for by any of the most common explanations which attribute dis-

\footnotetext{
* The research reported here was supported by funds granted to the Institute for Research on Poverty at the University of Wisconsin by the Office of Economic Opportunity, pursuant to provisions of the Economic Opportunity Act of 1964. I wish to thank David Dickens for his assistance with the statistical computations; I. Richard Savage for comments on an earlier draft; and Robert Alford and Michael Aiken for permission to use their data file on characteristics of cities. The conclusions are the sole responsibility of the author.
}

order-proneness to aspects of community organization. ${ }^{1}$

Using data on the demographic and organizational characteristics of all 673 cities in the contiguous United States with populations exceeding 25,000 in 1960 , in conjunction with information on the location of racial disorders during 1961-68, ${ }^{2}$ we ex-

\footnotetext{
${ }^{1}$ Studies which have sought to attribute the location of racial turmoil during the 1960's to political and economic characteristics of communities include Downes (1968), White (1968), and Maloney (n.d.).

2 Political and economic characteristics of the communities were obtained from the Alford-Aiken data file at Wisconsin. Sources of the disorder data were: Lemberg Center's Riot Data Review (1968), Congressional Quarterly's Civil Disorder Chronology (1967), and The New York Times Index. In order to reduce heterogeneity in the type of disturbance (which may reflect a particular set of underlying conditions), only instances of "spontaneous outbreaks" which were characterized by primarily Negro aggression were included in the analysis. This was the most common type of racial disorder in the 1960's, and the most severe
} 
amined a number of explanations. Specifcally, it was considered whether disorders are more likely events in communities characterized by high levels of social disorganization; whether rioting tends to occur where absolute deprivation is high and, hence, can be explained in terms of the material conditions of Negro life; alternatively, whether relative deprivation appears to produce the most intense frustration with the result that disturbances are likely where Negroes fare poorly in comparison to white residents; whether rioting may have its genesis in the gap between expectations and reality; or whether the turmoil of this period may be construed as a response of frustrated individuals when the institutionalized political channels for securing redress and articulating group interests are unresponsive. Several objective measures relating to each thesis were examined in order to ascertain the respective abilities of these alternative explanations to account for the distribution of the disorders. However, all were found to be inadequate.

Only two variables-the numerical size of the Negro population and a dummy term for region-proved to be related in a substantial manner to the location of the disorders. Together, these variables explain $46.8 \%$ of the variation in the dependent variable, the number of disorders in a city during the eight-year interval. The addition of 16 community characteristics, selected as indicators of the above explanations, to a regression equation containing the two variables accounted for only 4.5 additional percentage points of the total variation.

This result was attributed to the emergence, in recent years, of a number of factors which operate to promote geographic uniformity in the impact of stimuli that are frustrating to Negroes. (1) The activities of the federal government on behalf of Negro interests during the preceding decades are salient to the residents of every ghetto and may have sensitized them to this level of government. As a consequence, federal actions which are vacillatory in character or

disturbances were of this character. For additional detail on the coding of disorders, see Spilerman (1970b). These same materials are also used in the present investigation. otherwise insensitive to Negro concerns would be frustration provoking to Negroes irrespective of where they reside in the country. (2) The development of racial solidarity among Negroes-the recent growth of black consciousness and identity-has served to make the fate of Negroes in distant cities a matter of concern in all ghettos. (3) In addition to reinforcing the above processes through the provision of information relevant to these matters, the medium of television induces geographic uniformity by virtue of its own organizational structure. Through network news programming, the more graphic instances of discrimination and maltreatment of Negroes are transmitted to all sections of the country.

If, as a result of these considerations, a Negro individual is in fact apt to participate in a disorder irrespective of where he resides, then the location of instances of racial turmoil should reflect the numerical size of the Negro population in different communities (Spilerman 1970b:643). ${ }^{3}$ Moreover, since individuals would be responding primarily to frustrations generated outside their own communities, no other community characteristic should be related to the location of the disorders. Thus, although local conditions undoubtedly vary for Negroes, the results of the earlier study suggest that during the 1960's they have responded instead to frustrations which are felt by black persons in all communities, such as the slight attending the defeat of a rat control bill in Congress or the sight of Negro demonstrators being mistreated elsewhere.

The significance of the second variable, a dummy term for South, was attributed to the different traditions in race relations in the South and non-South. In the former region, past experiences of Negroes probably operate to reduce their expectations regarding the likelihood of rapid improvement in racial or economic matters, while the remembrance of past repression may lower the rate at which they permit their frustration to

3 The numerical size variable has frequently been used as an indicator of organizational complexity (cf. Blau and Scott, 1962:227; Blau, 1970; Aiken and Alford, 1970). In the present conceptualization, however, it is fundamentally a measure of the availability of participants. 
be translated into hostile outbursts. However, there is evidence that, apart from a constant term, the relationship between number of disorders and Negro population size is quite similar in the two regions. The partial correlation between these variables controlling for region (.668) is greater than the zero-order correlation between them (.586), suggesting that a covariance model (which formally assumes parallel lines) improves the relationship.

The above results derive from an analysis of the components of variance that are explained by different clusters of variables, which were selected to provide a comparison among the alternative explanations. The intent in the present study is to consider several related topics which were not raised in the prior report as they require a fundamentally different methodological perspective. In broad terms, our interest here will be to ascertain how satisfactory is the explanation which was proposed in the earlier analysis. This general concern will be pursued in the context of examining the following specific topics:

(1) There is the problem of specifying the form of the relation between Negro population size and the number of disorders in a city. This is necessary in order to measure the disorder-proneness of particular communities and ascertain how this value is likely to respond to a change in Negro population. More importantly, considering the intent of the paper, this specification is required for topics (2) and (3).

(2) If the explanation which was proposed in the introductory paragraphs is indeed correct, and Negro population size and a contextual variable for region are the sole community characteristics which are related to the location of disorders, there arises the question of accounting for the unexplained variation (which, in the previous analysis, amounted to $53.2 \%$ of the total variation). Does the magnitude of this value not mean that important variables have been neglected? This question is investigated in Section III by means of a simulation study.

(3) There is the problem of using these results to predict the locations of future disorders. The prediction of racial disorders has received some preliminary attention
(Maloney, n.d.), but a procedure which derives from empirically grounded theory is yet to be devised. However, if Negro population size and region are in fact the only variables necessitating consideration (and assuming that the causes of racial violence do not undergo essential change), an efficient predictive scheme can be constructed. This topic is addressed in Section IV. Considered together, the results from these analyses will permit an assessment to be made regarding the adequacy of the hypothesized explanation for the location of racial disorders in the 1960's.

\section{COMMUNITY DISORDER-PRONENESS AND NEGRO POPULATION SIZE}

In the previous analysis (Spilerman 1970b) we were primarily concerned with ascertaining the relative importance of a number of community characteristics in accounting for the distribution of disorders among cities. Because of the large number of variables that were considered, only the possibility of linear relationships-the simplest of interdependencies-was investigated. ${ }^{4}$ Now, having demonstrated the importance of Negro population size for community disorder-proneness (and the apparent insignificance of other community characteristics), a more detailed investigation into the shape of the relation is undertaken.

There are compelling reasons for expecting a distinctly non-linear form to characterize the dependence of disorder-proneness upon Negro population size. At the lower end of the Negro population continuum, given the Negro protest character to racial turmoil during the 1960's, the human resources necessary to produce a racial incident of sufficient magnitude to qualify as a disorder would seem to be lacking. Consequently, one should notice a threshold effect in the data, a critical Negro population size below which racial disorders fail to develop.

At the upper end of the Negro population

${ }^{4}$ Transformations were used but for the purpose of linearizing particular relationships for statistical analysis. The emphasis was not on the substantive meaning of the functional form. 
continuum, other considerations suggest that a ceiling effect may operate to limit the number of disorders that can occur in a community in a fixed time interval. In part, a ceiling effect would be an artifact of definitional difficulties with the concept of a disorder. When several disturbances occur in a city within a short time period, they may be recorded as a single incident of long duration or high severity. ${ }^{5}$ Aside from this definitional problem, however, there are substantive considerations which argue for the presence of a ceiling effect.

First, in the days subsequent to a disturbance, the police and other agencies of social control are probably sensitized to the possibility of further violence. As a result, they may avoid actions which antagonize ghetto residents and, at the same time, remain prepared to respond in force to incipient riot situations. "Keeping the lid on" in this way is one activity which would serve to limit the number of outbreaks that can occur in a city in a specified time interval.

A second reason for expecting fewer disorders in large ghettos than a linear relation with Negro population size would predict derives from the conceptual model presented earlier, namely, the thesis that Negroes were responding primarily to stimuli which are geographically diffuse in their impact. On first impression this might appear as support for the existence of a linear relation between Negro population size and racial turmoil; however, introduction of the additional consideration of disorder severity alters that inference. There is some evidence that severe disturbances, which involve many individuals, have occurred to a disproportionate extent in the larger ghettos (Spilerman 1970a). Assuming the effect of geogra-

\footnotetext{
5 Although the riots in Watts, Detroit, and Newark each lasted for several days, they are recorded in most compilations as single events. Other disturbances, which consisted of a sequence of incidents over more than one day, are sometimes listed as multiple disorders. For coding purposes, it was arbitrarily decided that reports of multiple disturbances in a city which are separated by less than five days would be recorded as a single event. The only other consideration given to disorder severity was the requirement of a minimum level of turmoil for inclusion in the study. An incident had to involve at least 30 individuals and result in some violence or destruction to be classified as a disorder.
}

phic uniformity to mean that an individual is equally apt to participate in a disorder irrespective of where he resides (so long as the city exceeds the critical threshold in Negro population), in communities with large Negro populations he would be more likely to discharge this proclivity in severe disorders involving many participants. These communities, in turn, would witness fewer disturbances than expected from a linear relation with Negro population size, though of a more serious nature. Consequently, at the upper end of the Negro population scale, either because of a saturation effect to the number of distinct disorders which a city can sustain ${ }^{6}$ or because disorders in large ghettos tend to encompass many individuals, the marginal increase in community disorder-proneness, per additional Negro individual, should decrease.

Support for these contentions is found in Table 1. Row 4 of this table shows the average number of disorders which occurred in a city during 1961-68, with the cities categorized by Negro population size. As the linear correlation reported in Section I between number of disorders and Negro population (.586) suggests, disorder-proneness exhibits a consistent tendency to increase with this variable, varying from zero disturbances per city for communities with fewer than 1,000 Negroes, to an average of 4.95 disorders per city for the 19 communities with more than 100,000 Negroes. Row 5 presents the racial disturbance rate per 1,000 Negroes in a category. These values were computed by dividing the total number of disorders in a category (Row 1) by the aggregate Negro population for the cities (Row 3). The results provide evidence both for the necessity of a minimum critical size before racial incidents of sufficient magnitude to be labeled as disorders can occur, and for the contention that the disorder rate is constrained by a ceiling effect. Disorders

\footnotetext{
${ }^{6}$ Since the disturbances were compiled primarily from news accounts, there is also a possibility that the incremental news value of an additional disturbance in a city decreases as a function of the number of disturbances which already occurred. It is unlikely, however, that this consideration can account for a saturation effect since even the most disorder-prone cities (Chicago, New York) have averaged fewer than three reported disorders per year over the eight-year interval.
} 
Table 1. Disorder Data for Cities with 25,000 or More Inhabitants, by Negro Population Size, 1961-1968.

\begin{tabular}{|c|c|c|c|c|c|c|c|c|c|}
\hline & & \multicolumn{8}{|c|}{ Negro Population of City (in thousands) } \\
\hline & & $\begin{array}{l}0.00- \\
1.00\end{array}$ & $\begin{array}{l}1.00- \\
2.50\end{array}$ & $\begin{array}{l}2.50- \\
5.00\end{array}$ & $5-15$ & $15-25$ & $25-50$ & $\begin{array}{l}50- \\
100\end{array}$ & $100+$ \\
\hline 1) & Number of Disorders $\mathbf{s}^{\mathbf{a}}$ & 0 & 11 & 31 & 85 & 37 & 49 & 34 & 94 \\
\hline 2) & Number of Cities & 261 & 93 & 80 & 118 & 44 & 37 & 21 & 19 \\
\hline 3) & $\begin{array}{l}\text { Aggregate Negro } \\
\text { Population }(1,000 \text { 's })^{b}\end{array}$ & 92 & 151 & 300 & 1,076 & 846 & 1,289 & 1,490 & 6,212 \\
\hline 4) & Disorders per City & 0 & .118 & .388 & .720 & .841 & 1.324 & 1.619 & 4.947 \\
\hline 5) & $\begin{array}{l}\text { Disorders per } 1,000 \\
\text { Negroes }\end{array}$ & 0 & .073 & .103 & .079 & .044 & .038 & .023 & .015 \\
\hline
\end{tabular}

${ }^{\text {a }}$ Sources of the disorder data are The New York Times Index, Congressional Quarterly's Civil Disorder Chronology (1967), and the Lemberg Center's Riot Data Review (1968).

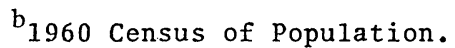

per individual increase with Negro population size until the category 2,500-5,000 and thereafter decrease.

The preceding discussion, together with the empirical evidence from Table 1, suggests that the relationship between number of disorders in a city (D) and Negro population size $(\mathrm{N})$ should be S-shaped. With a curve of this form, the rate of increase in disorder-proneness as a function of Negro population would be low among cities with small Negro populations, high among cities with intermediate size Negro populations, and low again among large ghettos. The most common S-shaped curve is the logistic (Lotka, 1956:68-70; Coleman, 1964:43); however, the properties of this curve are too restrictive for use with the disorder data. ${ }^{7}$ A more general S-shaped function,

$$
\mathrm{D}=\mathrm{e}^{\left[a-\frac{\beta}{\mathrm{N}^{2}}\left(\mathrm{e}^{-\gamma \mathrm{N}}\right)-\frac{\delta}{\mathrm{N}}\left(1-\mathrm{e}^{-\gamma \mathrm{N}}\right)\right]}
$$

where $a, \beta, \gamma$ and $\delta$ are paremeters, was therefore constructed. Since the S-form is not compatible with the notion of an addi-

\footnotetext{
${ }^{7}$ The logistic curve requires the inflection point to be midway between zero disorders and the upper asymptote (the predicted maximum number of disorders). Furthermore, the two limbs of the curve are constrained to be symmetric about the inflection point. Since there is no reason to expect the disorder data to satisfy these restrictions, a more flexible S-curve was constructed.
}

tive constant term for region, this function was fit separately to the disorder data from each region. The resulting curves are presented in Figure 1.8

To measure the explanatory power of the Negro population variable, we calculated the proportion of variation in number of disorders accounted for by these curves. In the non-South, $73 \%$ of the variation is explained by the nonlinear regression; among Southern cities 34\% of the variation can be attributed to Negro population size. The curves also indicate that the specification of a covariance model, which was used in the previous study, provided a reasonable approximation to the true relationship. Beyond a Negro population equal to 10,000 , the curves are nearly parallel. What the covariance model obscured, however, is the very different $\mathrm{R}^{2}$ values for the two regions.

According to these curves, community disorder-proneness increases most rapidly with Negro population size for cities with approximately 3,500 Negroes in the non-South, ${ }^{9}$

${ }^{8}$ A nonlinear regression program (Gaushaus) was used to minimize the residual sum of squares by the method of steepest descent. For details on the program, consult the University of Wisconsin Computing Center's Users' Manual (1966). Note, incidently, that while the curve is S-shaped over the range of Negro population values which characterize American cities, it does not have this form over the entire real line.

${ }^{9}$ The rate of increase of a curve at a particular point can be determined from its first derivative. 
FIGURE 1. Relationship Between Racial Disturbances During 1961-68 And Negro Population Size

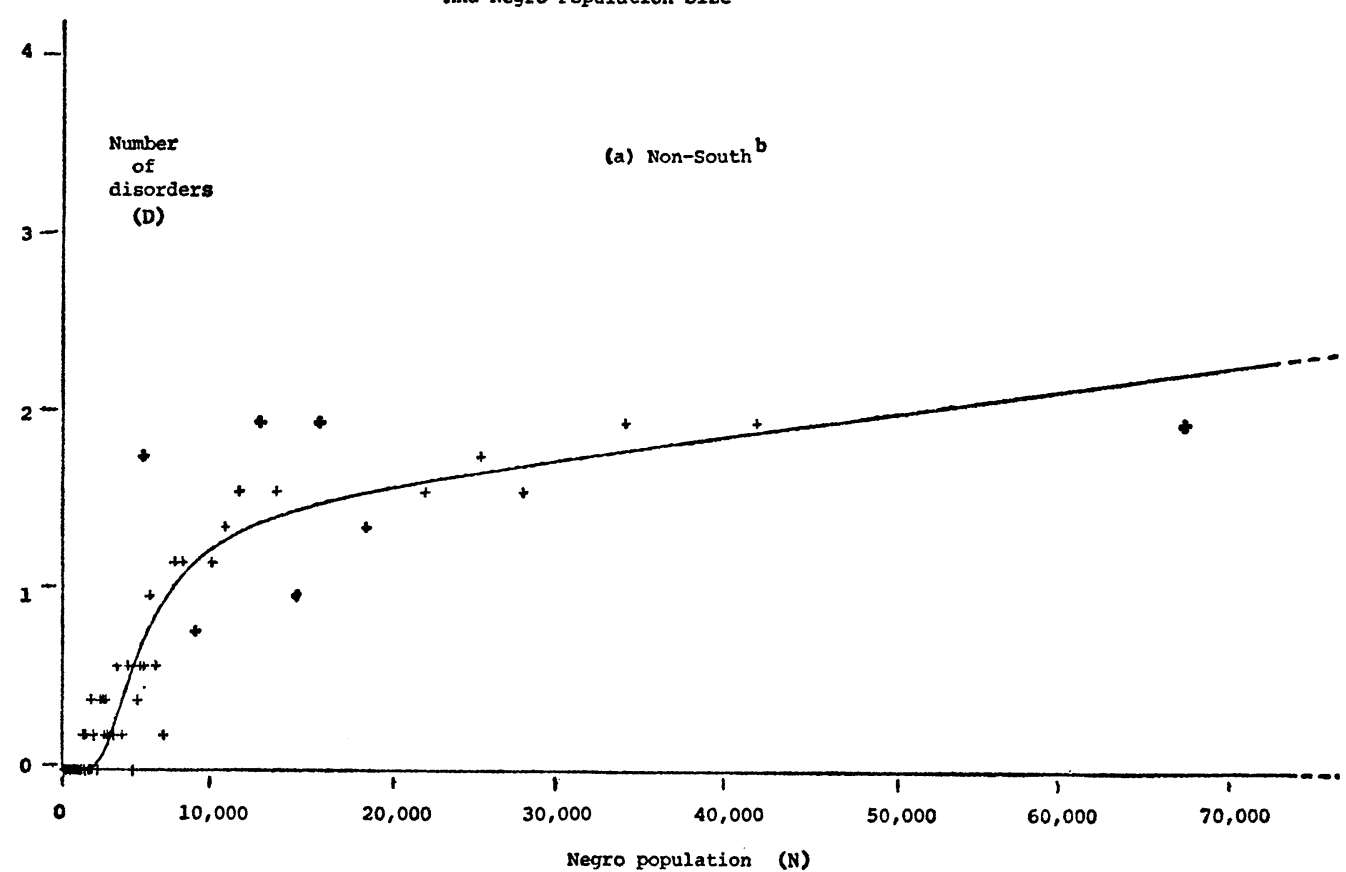

Negro population (N)

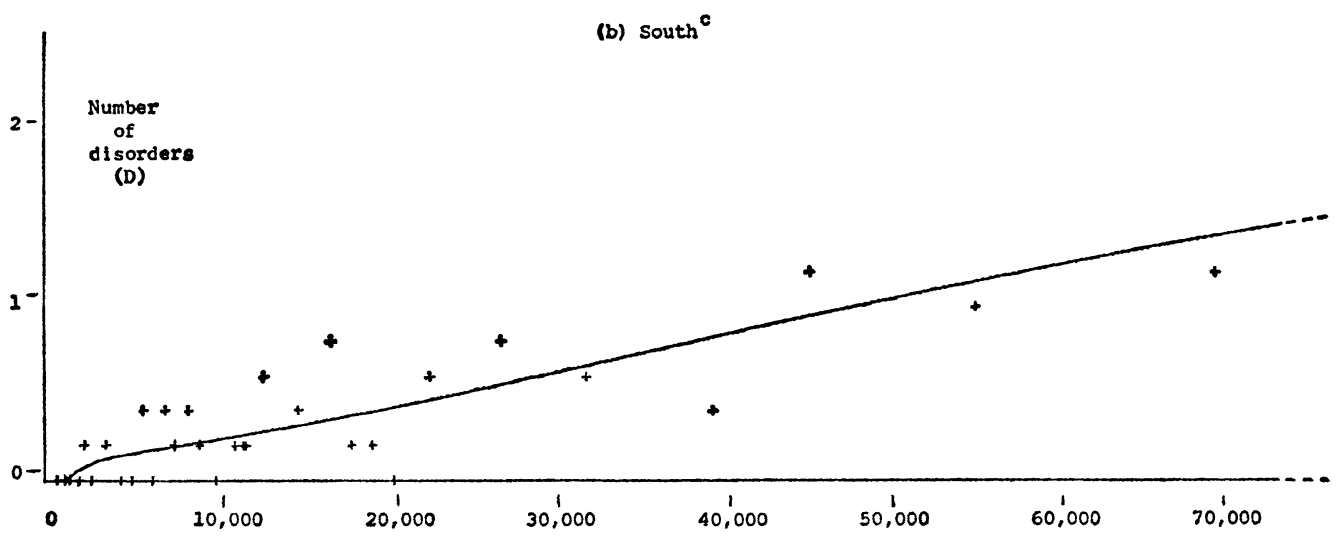

Negro population (N)

a. Each point represents five citles that are adfacent in Negro population size. The group value for Negro population is the ant -108 of the mean of the logged flgures. The group value for number of disorders is the arithmetic mean. (Grouplng is for presentation purposes only; all analyses were performed on the individual city values.)

b. Parameter values for the non-South are: $\alpha=2.649, \beta=1.708 \times 10^{7}, \delta=3.271 \times 10^{5}, \gamma=6.95 \times 10^{-6}$

c. Parameter values for the South are: $\alpha=1.270, B=2.103 \times 10^{6}, \delta=6.615 \times 10^{4}, Y=5.23 \times 10^{-5}$

Evaluating the derivative of equation (1) for the non-South at $\mathrm{N}=3,500$ and at $\mathrm{N}=100,000$ yields the following result: Disorder-proneness changed by .310 expected disorders per city (for the eightyear interval) with an increase of 1,000 Negroes at the first population value, and by .014 disorders per city with an identical sized increase in Negro population at the second value, and 1,000 Negroes in the South. No special significance should be attributed to these precise values, however, since by fitting different S-shaped functions minor variations will result in the points of maximum increase. What is important, and is particularly evident from the plotted points for 
the non-South, is the S-shaped character of the relation.

\section{WHAT ABOUT THE UNEXPLAINED VARIATION?}

The $R^{2}$ values associated with the $S$ curves indicate that the single variable, Negro population size, explains $73 \%$ of the variation in number of disorders in the nonSouth, and $34 \%$ in the South. These are substantial proportions; nevertheless, there is still the question of accounting for the residual variation. Is it the case that by considering additional community characteristics the proportion of explained variation can be increased? Or, alternatively, is it possible that the total proportion of variation which can be theoretically explained is actually less than one?

The commonly employed measure of the inadequacy of an explanation, $1-R^{2}$, is predicated upon an underlying explanatory model which is fundamentally deterministic. The concept of randomness is employed in that formulation to compensate for errors resulting from inadequate measurement and neglected effects. Presumably, by improving data quality and incorporating additional variables into an explanation, the proportion of explained variation could be increased and, theoretically, made to approach the value "one."

In contrast to that view of randomness as disturbance, a process may be conceptualized as inherently stochastic, and this type of explanatory model is consistent with there being a complete explanation (in the sense that all relevant knowledge has been incorporated) in which the $\mathrm{R}^{2}$ value is less than one. As an illustration of inherent randomness, Ernest Nagel (1961:332) writes, many physicists "maintain that sub-atomic processes . . . are characterized by absolute chance, so that, for example, the emission of particles by radioactive substances is regarded as 'a process due to the spontaneous decomposition of its atoms' (Plank, 1936: 52)." In this view, knowing the mass of a radioactive substance is tantamount to having complete knowledge about the number of disintegrations which will occur in a specified time interval, since no other variables are relevant to the process of radio- active decay. Nevertheless, if, after the fact, the number of disintegrations is regressed against mass (the observations being different sized pieces of the same radioactive substance), the resulting value of $\mathrm{R}^{2}$ will be less than one. It is neither possible to predict the exact number of disintegrations which will occur, nor which particles will decay, although the process is completely specified by the mass variable.

The phenomenon of hostile outbursts has frequently been cast in an analogous framework (Smelser, 1963; Lieberson and Silverman, 1965; Spilerman, 1970b). In this view, the structural conditions which create a conducive context for racial disorder are to be distinguished from the precipitating incidents. The structural conditions are amenable to analysis in terms of community level variables; for example, disorder-proneness may be consequent upon economic structure, political organization, or demographic characteristics. However, disorderproneness is a measure of the expected number of outbreaks in a time interval. The actual number is dependent upon the occurrence of precipitating incidents, which are conceived of as random events. Assuming this conceptualization of disorders, the 1$\mathrm{R}^{2}$ values reported for the regions would overestimate the true proportions of residual variation which can be explained by the inclusion of additional community characteristics. Just what values of $\mathrm{R}^{2}$ are consistent with a complete explanation of disorder outbreaks is the subject of the present section.

We approach this question by means of a simulation methodology. This strategy requires that we first ascertain what $\mathrm{R}^{2}$ value is associated with a complete explanation of the location of disorders, assuming that disorder-proneness is a function of Negro population only. Afterwards, the proportion of variation explained by Negro population size in the actual disorder data will be compared with the estimates of the maximum attainable values for the regions.

For the purpose of simulation, it was therefore assumed that the disorder-proneness value for a city $\left(\lambda_{\mathrm{i}}\right)$ depends only upon its Negro population size and, moreover, is specified in terms of that variable by equation (1). Using this formula, an expected number of disturbances for the eight-year 
period was calculated for each city. ${ }^{10} \mathrm{~A}$ hypothetical distribution of disturbances was then generated from these expected values under the assumption that hostile outbursts follow a Poisson process with parameter value $\lambda_{\mathrm{i}}$ for city i. ${ }^{11}$ Considering the manner by which this hypothetical distribution was constructed, it is evident that only Negro population size can be related to the number of disorders in a city since no other variable was involved in the simulation. However, because the individual outbreaks are random events, the proportion of variation in this hypothetical distribution which is explained by Negro population size will necessarily be less than one.

To ascertain what value of $\mathrm{R}^{2}$ is consistent with an explanation in which Negro population size is the sole determinant of disorder-proneness, the above simulation was carried out ten times for non-Southern and Southern cities. For each of the resulting distributions, the number of disorders assigned to a city was regressed against Negro population size, with the S-shaped function (Equation 1) fit by means of the non-linear estimation routine. Consequently, the $R^{2}$ values associated with these regressions provide independent estimates of the maximum proportion of variation which can be explained by Negro population size when it

${ }^{10}$ Under the assumption that disorders are random (Poisson) events, with disorder-proneness value for city i during 1961-68 equal to $\lambda_{i}$, the expected number of disorders for this period would also equal $\lambda_{1}$ (see Feller, 1957:209). Thus, the $\lambda$-values are the $y$-coordinates for the cities from the curves presented in Figure (1).

11 The simulation was performed for each city in the following manner: Using the Poisson formula,

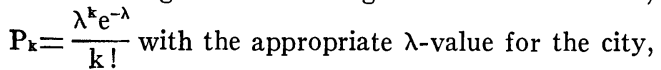

the probability of $k=1,2, \ldots, 20$ events was calculated. These values were combined to provide a cumulative probability distribution:

$\mathrm{f}_{0}=\mathrm{P}_{0} ; \quad \mathrm{f}_{1}=\mathrm{f}_{0}+\mathrm{P}_{1} ; \quad \mathrm{f}_{2}=\mathrm{f}_{1}+\mathrm{P}_{2} ; \ldots$; $\mathrm{f}_{19}=\mathrm{f}_{18}+\mathrm{P}_{19} ; \quad \mathrm{f}_{20}=1$.

The resulting sequence is therefore nondecreasing, and $f_{k}$ measures the probability of $k$ or fewer events. A random number $r$, rectangular between zero and one, was then generated by the computer program, and a hypothetical number of disorders equal to $j$ was assigned to the city, where $j$ satisfies the relation $\mathrm{f}_{\mathrm{j}-1}<\mathrm{r} \leqslant \mathrm{f}_{\mathrm{j}}$. This procedure was repeated for each of the 673 cities with the $\lambda$ value determined by the S-curve for the appropriate region. is assumed that this variable alone determines community disorder-proneness, and that precipitating incidents are random events.

The mean and variance of the $R^{2}$ values generated by the simulation procedure are presented in Columns 2 and 3 of Table 2. Referring to the mean figures, we conclude that, on the average, the maximum proportion of variation which can be explained by Negro population size is .75 in the nonSouth and .48 in the South, even though all information about the generative process is contained in that variable. As a percentage of these estimates of the maximum explainable proportions, $98 \%$ of the variation in the actual disorder data is accounted for by Negro population size in the non-South, and $72 \%$ in the South (Column 4). Consequently, this single variable seems to produce an even more satisfactory explanation of the disorder distribution than was apparent from the unadjusted $\mathrm{R}^{2}$ values (Column 1). The value for the non-South is consistent with the hypothesized explanation being complete for this region. For the South, however, although the $\mathrm{R}^{2}$ value is improved, the operation of additional factors is suggested. ${ }^{12}$

To pursue these questions from a different perspective, we considered the explanatory contribution from 16 additional community characteristics. These variables have been justified elsewhere (Spilerman, $1970 \mathrm{~b})$ as being indicators of social disorganization, absolute deprivation of Negroes, relative deprivation, and lack of political responsiveness by the municipality. ${ }^{\mathbf{1 3}}$ Since

12 These conclusions must be cautiously stated. First, they are based upon the mean of the $\mathrm{R}^{2}$ values from the simulation. As indicated by the standard deviations in Column 3, quite different individual values of $\mathrm{R}^{2}$ can result from the same assumptions. Second, the calculations for the nonSouth indicate only that the thesis concerning the lack of importance of other community characteristics has not been disconfirmed, not that it is correct.

${ }^{13}$ The following variables were used. Indicators of social disorganization: percent change in total population; percent change in nonwhite population; percent of housing units dilapidated in 1950 (1950 Census of Population). Indicators of absolute deprivation: percent of nonwhite males employed in traditionally Negro occupations (service workers, household workers, laborers); nonwhite male unemployment rate; nonwhite median family income; 
Table 2. Observed and simulated squared correlation coefficient $\left(R^{2}\right)$, by Region.a

\begin{tabular}{|c|c|c|c|c|c|}
\hline Region & $\begin{array}{c}\text { (1) } \\
\text { Observed } \\
\mathrm{R}^{2} \text { value }^{\mathrm{b}}\end{array}$ & $\begin{array}{c}\text { (2) } \\
\text { Mean of } \mathrm{R}^{2} \cdot \mathrm{s} \\
\text { from simulation }\end{array}$ & $\begin{array}{l}\text { (3) } \\
\text { Standard deviation } \\
\text { of simulated } R^{2} s^{b}\end{array}$ & $\begin{array}{l}(4) \\
(1) /(2)\end{array}$ & $\mathrm{N}^{\mathrm{C}}$ \\
\hline Non-South & 73.0 & 74.7 & 4.1 & .98 & 501 \\
\hline South & 34.4 & 47.8 & 11.1 & .72 & 172 \\
\hline
\end{tabular}

\footnotetext{
a Ten simulation runs were made for each region. See text for description of the procedure.

bentry is multiplied by 100.

$C_{\text {All }}$ cities in the contiguous U.S. with total population greater than 25,000 in 1960 .
}

1960 census data on Negro population characteristics are not available for cities with fewer than 1,000 Negroes, the present analysis was limited to the 413 communities (from among the original 673) with Negro populations in excess of this figure. Also, since non-linear estimation is cumbersome with several independent variables, a linear approximation to the S-shaped curve, in the form of an additive function in $\log \mathrm{N}$ and $(\log \mathrm{N})^{2}$, was used. This approximating function reproduces the shape of the S-curve (Figure 1), except for the lower bend. However, because of the required deletion of communities with small Negro populations, the discrepancy between the curves was expected to be negligible.

Columns 1 and 2 of Table 3 present results from fitting the S-curve and the polynomial in $\log \mathrm{N}$ to disorder data from the 413 communities. In Column 1, the $\mathrm{R}^{2}$

nonwhite median education. Indicators of relative deprivation: percent of nonwhite males employed in traditionally Negro occupations divided by white figure; nonwhite median family income divided by white income; nonwhite unemployment rate divided by white rate; nonwhite median education divided by white education; percent nonwhite $(\sqrt{\mathrm{x}})$. Indicators of political responsiveness: population per councilman; percent of city council elected at large; presence of nonpartisan elections; presence of mayor-council government (all variables in this cluster are from The Municipal Yearbook, 1967).

Percent nonwhite was included with the indicators of relative deprivation because an alternative explanation, which emphasizes interracial competition, can also be associated with this cluster of variables. See Spilerman (1970b:641). values are shown for the S-curve, which was estimated by the non-linear method; while in Column 2 the corresponding values for the approximating polynomial, ${ }^{14}$ estimated by least squares, are presented. It is evident from these entries that the polynomial in $\log \mathrm{N}$ provides a reasonable approximation in each region. Column 3 contains the $R^{2}$ values from a regression equation in which the 16 community characteristics have been added to the $\log \mathrm{N}$ terms. Inclusion of these 16 variables is seen to explain only 3.9 additional percentage points of the variation in the non-South, but 9.2 percentage points in the South. Consequently, the results in Table 3 present further evidence for the contention that different processes were operating in the two regions. The thesis that Negro population size is the sole community characteristic relevant to explaining the number of disorders in a city again appears to be supported only with respect to the non-South. Negro population size is also a variable of immense importance in the South, but it apparently is not the only determinant of disorder-proneness.

${ }^{14}$ In the previous study (Spilerman 1970b), the dependent variable was transformed according to $\sqrt{\mathrm{D}^{\prime}+\mathrm{r} / 2}$, where $\mathrm{D}^{\prime}=\mathrm{D}$ (the number of disorders in a city) for $\mathrm{D} \leqslant 5$, and $\mathrm{D}^{\prime}=5$ for $\mathrm{D}>5$. The square root transform is recommended for a Poisson variate to stabilize its variance (Goulden, 1952: 98). In this study, since the shape of the curve is being emphasized, the untransformed variable D is used. With respect to the significance of independent variables, the results with the two versions of the dependent variable are identical. 
Table 3. Percent of Variance in Number of Disorders Explained by Negro Population Size and by Subsequent Addition of 16 Community Characteristics, by Region.

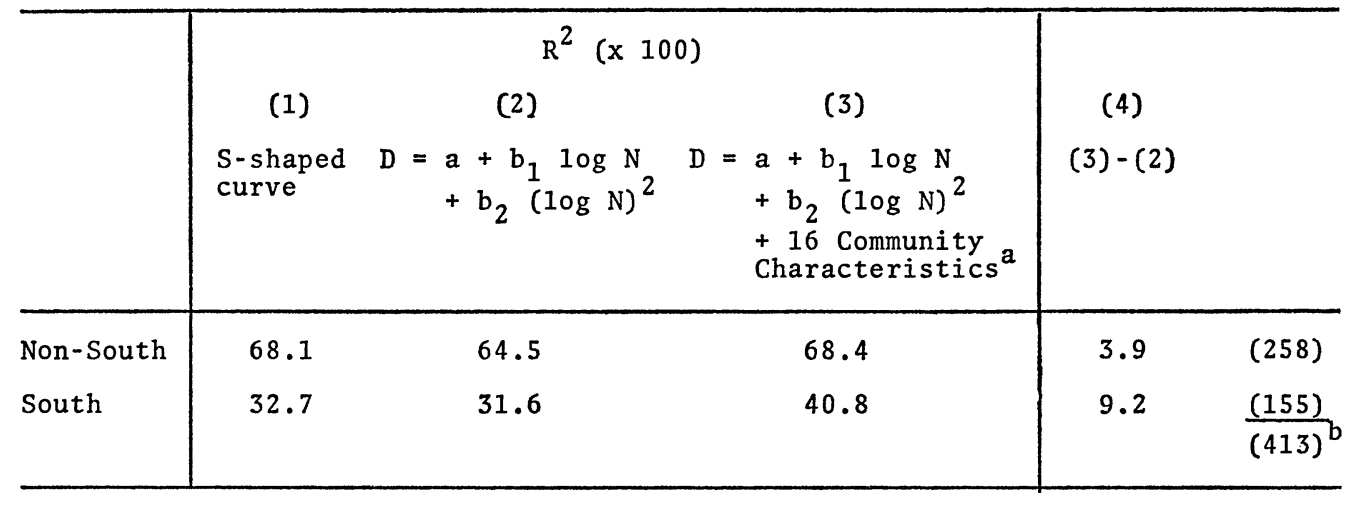

${ }^{a}$ See Table 4 for listing of the 16 community characteristics.

$\mathrm{b}_{\mathrm{A}} 11$ cities in the contiguous U.S. with total population greater than 25,000 and Negro population greater than 1,000 in 1960 .

Which community characteristics are related to the distribution of racial disorders in the South? To investigate this question, we ran separate regressions with the variables from each indicator cluster. The results are reported in Table 4. Column 1 presents the proportion of variation in number of disorders accounted for by each cluster acting separately. In Columns 2 and 3 the unique components of variation explained by a cluster, controlling for the variables in another, are shown. In Column 2 the unique contribution to $\mathrm{R}^{2}$ made by the two Negro population variables is presented; while in Column 3 the unique contribution of each cluster, controlling on the Negro population terms, is shown.

The large magnitude of the entries in Column 2 is not surprising since the preceding analyses have already underscored the paramount importance of the Negro population variables. Since the model of disorderproneness we are using attributes conceptual priority to the Negro population variables (Spilerman, 1970b:643-645), the relevant findings for assessing the roles played by different clusters of community characteristics are the entries presented in Column 3. From these values it is apparent that the indicators of political responsiveness substantially account for the additional variation explained by the community characteristics in the South.

The significance of this cluster is entirely attributable to two of its four variablesthe dummy variables for nonpartisan vs. partisan elections, and mayor-council vs. other administrative structure. It was hypothesized (Spilerman, 1970b:641) that partisan elections and a mayor-council structure form a consistent pair, in that each arrangement should promote political responsiveness to minority group interests. With this interpretation of the indicators, the results are contradictory. Controlling on the Negro population terms and on the other variables in the political structure cluster, number of disorders is positively correlated both with the presence of nonpartisan elections $(r=.241)$, and with a mayor-council structure $(\mathrm{r}=.177)$.

We may speculate upon a different interpretation of these indicators. Crain et al. (1969) have suggested an alternative formulation of the structural determinants of municipal responsiveness which also involves these two variables. ${ }^{15}$ In an investigation of the relevance of community political structure to the fluoridation decision, they conclude that an elected official, such as a mayor, in a nonpartisan town is highly vulnerable to public opinion and, therefore, likely to refrain from taking controversial actions. "When elections are partisan, the office holder can rely on a party endorsement

\footnotetext{
${ }^{15} \mathrm{I}$ am indebted to Robert Alford for bringing the Crain, Katz, and Rosenthal discussion to my attention.
} 
Table 4. Percent of Variance in Number of Disorders Explained by Cluster Alone (1); by Non-white Population Variables When Entered after Cluster (2); and by Cluster When Entered after Non-white PopuLATION VARIABLES (3); FOR SOUTH.

\begin{tabular}{|c|c|c|c|}
\hline $\begin{array}{l}\text { Variable } \\
\text { Clustera }\end{array}$ & (1) & (2) & (3) \\
\hline $\begin{array}{l}\text { Non-white } \\
\text { Population }\end{array}$ & 31.6 & $\cdots$ & $\cdots$ \\
\hline $\begin{array}{l}\text { Social Dis- } \\
\text { organization }\end{array}$ & 0.7 & 32.2 & 1.3 \\
\hline $\begin{array}{l}\text { Absolute } \\
\text { Deprivation }\end{array}$ & 5.9 & 26.9 & 1.2 \\
\hline $\begin{array}{l}\text { Relative } \\
\text { Deprivation }\end{array}$ & 13.9 & 20.0 & 2.3 \\
\hline $\begin{array}{l}\text { Politica } 1_{f} \\
\text { Structure }\end{array}$ & 20.1 & 17.5 & 6.0 \\
\hline $\begin{array}{l}\text { A11 Clusters } \\
\text { Except Non- } \\
\text { white Popula- } \\
\text { tion }\end{array}$ & 32.3 & 8.5 & 9.2 \\
\hline A11 Clusters & 40.8 & $\ldots$ & $\cdots$ \\
\hline
\end{tabular}

a All variables are from the 1960 Census of Population unless otherwise indicated in notes $b-f$.

b Non-white population variables are: Log(non-white population), [Log (non-white population) $\left.{ }^{2}\right]$.

c Indicators of social disorganization are: Percent change in total population; percent change in non-white population; percent of housing units dilapidated in 1950 (1950 Census of Population).

d Indicators of absolute deprivation are: Percent of nonwhite males employed in traditionally Negro occupations (service workers, household workers, laborers); non-white male unemployment rate; non-white median family income; non-white median education.

e Indicators of relative deprivation are: Percent of nonwhite males employed in traditionally Negro occupations divided by white figure; non-white median family income divided by white income; non-white unemployment rate divided by white rate; non-white median education divided by white education; percent non-white $(\sqrt{\mathbf{x}})$.

Indicators of political responsiveness are: Population per councilman; percent of city council elected at large; presence of nonpartisan elections; presence of mayor-council government (all variables in this cluster are from the Municipal Yearbook, 1967).

to guarantee a certain stability in his support ... In contrast, in a non-partisan system any group of citizens can agree to find a candidate for office and support him ..." (Crain et al., 1969:191-92). As a consequence, "the lack of a strong executive [in a nonpartisan/mayor-council town] might mean an effort to shirk responsibility for action in an area of controversy ...." (Crain et al., 1969:203).

Much of the racial turmoil in the South has been related to civil rights protests-to demands by Negroes for integration, municipal jobs, and higher wages-in short, to issues requiring political negotiation. According to Crain et al.'s thesis, the communities which would be least capable of compromising with Negro protestors would be the nonpartisan/mayor-council cities. This argument therefore suggests an interaction effect between the two dimensions of political organization-a mayor-council arrangement should have very different meaning for the prospects of resolving community conflict in a party system than where elections are nonpartisan. Examination of the data provides some support for their contention. Controlling on the Negro population variables, presence of nonpartisan elections adds .36 expected disorders to a city (b-coefficient); presence of a mayor-council structure adds .13 expected disorders; while the presence of a nonpartisan/mayor-council arrangement adds an additional .41 expected disorders above the additive effects. However, although these regression coefficients are consistent with the interaction thesis, owing to the small number of nonpartisan/ mayor-council cities (15 among 155 Southern cities), the interaction term is not significant.

\section{PREDICTING DISORDERS FROM NEGRO POPULATION SIZE}

The above findings, particularly for the non-South, suggest an efficient procedure for predicting the location of future disorders. Assuming that racial disturbances will continue to be responses to the same type of stimuli which caused the spate of disorders during 1961-68 (namely, frustrations which are uniformly felt by Negroes in all sections of the country), then predictions based upon Negro population size alone should provide an accurate estimate of the distribution of future disorders.

To evaluate the utility of this approach, we used disturbance data for 1961-67 to predict the location of the 1968 disorders. Separate S-shaped curves were estimated for each region from the earlier data; then, using these curves, we calculated a disorderproneness value for each community. The resulting values therefore define the relation between Negro population and outbreaks of racial violence which existed during 196167. In order to predict the locations of the 1968 disturbances, these values were 
standardized to sum to the actual number of disorders in 1968. This is necessary because the explanations considered in this investigation relate to the distribution of disorders among cities, not to the absolute number which occurred in the nation.

How good are the estimates produced from these calculations? Since the prediction for a city is usually a fraction (expressing an expected number of incidents in 1968), while the actual data are integers (the number of disorders which occurred in a city), only aggregate figures for groups of cities can be meaningfully compared. Table 5 presents the predicted and empirical distributions of disorders for 1968, by region. In each panel of this table the cities have been grouped into six categories, ranging from the most disorder-prone communities (those with largest Negro populations) to the least disorder-prone (cities with smallest Negro populations). The divisions were selected to place an equal number of predicted disorders in each cell, except for the most disorderprone category. It was arbitrarily decided to place 15 cities in that category in the non-South, and 5 in the South. Otherwise, too few cities would be present to permit stable estimates.

Once again very different results characterize the two regions. In the non-South, the empirical distribution of disorders (Column 2) appears quite similar to the predicted distribution (Column 1) $\left(\chi_{5}^{2}=1.85\right.$, insignificant at the .10 level) and, moreover, the departures from the predicted values do not show a systematic trend. By contrast, in the South, the predictions from the 1961-67 distribution result in a poor match with the actual events $\left(\chi_{5}^{2}=20.8\right.$, significant at the .001 level). It is also noteworthy that the deviations are clearly systematic here: There was a tendency in 1968 for small Negro population communities to become increasingly disorder-prone, relative to larger ghettos in this region.

These findings further underscore the results obtained in Section III, namely, while Negro population size may substantially account for the explainable variation in number of disorders in the non-South, the etiology of disturbances in the South is not so simply dealt with. One possibility, regarding the shift in disorder-proneness in the South to small Negro population communities, is that more accurate data are available for 1968 than for earlier years. Indeed, the Lemberg Center's Riot Data Review was first published for 1968 and this source is far more comprehensive than the compilations of earlier disorders. However, deficiencies in the data are unlikely to be responsible

Table 5. Predicted and Actual Number of Disorders for 1968, by Negro Population Size, Largest (1) to Smallest (6), by Region.

\begin{tabular}{|c|c|c|c|c|c|c|}
\hline $\begin{array}{l}\text { Negro } \\
\text { Popul. } \\
\text { Size }\end{array}$ & Predicted $c$ & $\begin{array}{c}\text { Non-South } \\
\text { (2) } \\
\text { Actual }\end{array}$ & $\stackrel{N}{\text { (Cities) }}$ & Predicted $^{(1)}$ & $\begin{array}{c}\text { South }^{\mathrm{b}} \\
(2) \\
\text { Actual }\end{array}$ & $\stackrel{N}{N}$ \\
\hline 1 & 32.6 & 29 & 15 & 12.2 & 3 & 5 \\
\hline 2 & 13.0 & 15 & 17 & 6.6 & 5 & 5 \\
\hline 3 & 13.5 & 14 & 23 & 6.1 & 5 & 8 \\
\hline 4 & 13.5 & 15 & 27 & 6.0 & 6 & 14 \\
\hline 5 & 13.3 & 11 & 34 & 5.7 & 11 & 33 \\
\hline 6 & 13.2 & 15 & 385 & 5.3 & 12 & 107 \\
\hline Total & 99.1 & 99 & 501 & 41.9 & 42 & 172 \\
\hline
\end{tabular}

a parameter values of S-curve fit to 1961-67 disorder data from non-South are: $\alpha=$ $2.212 ; \beta=1.309 \times 10^{7} ; \delta=2.898 \times 10^{5} ; \gamma=8.344 \times 10^{-6}$.

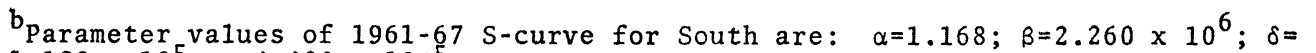
$1.120 \times 10^{5} ; \gamma=4.420 \times 10^{-5}$.

$\mathrm{c}_{\text {Total }}$ predicted disorders were standardized to sum to empirical total for the region in 1968 . 
for the noted shift because of the regional difference in results. Presumably, any bias in compilations of the earlier disorders toward underrepresenting disturbances in small communities would also hold for the nonSouth.

A more likely possibility concerns the particular experiences of Negroes in small Southern communities. Small communities in this region have been notorious for their extensive control over Negro residents through the use of economic intimidation and repressive police practices (Vander Zanden, 1966:232-34). The adaptation by Negroes to this circumstance has commonly been one of passivity and servility (Matthews and Prothro, 1966:262). For example the "folk Negro" stereotype is associated principally with small towns and rural places in the South, not with metropolitan areas. For this reason, Negroes in small Southern communities may have lagged behind those living elsewhere in developing racial solidarity, and in collectively expressing outrage at instances of the brutal treatment of black persons. However, 1968 was probably a watershed year for residents of these communities because of the assassination of Martin Luther King. The high esteem in which he was held by Negroes is well known (e.g., Brink and Harris, 1967: 54); also, his movement was Southernbased, which may have made his career particularly salient to Negroes in this region. Thus, his death may have stunned these previously passive persons into participating in the black consciousness which had been developing elsewhere in the country. These comments provide one argument which is consistent with the noted increase in disorder-proneness among small Negro population communities in the South, relative to large ghettos.

An alternate possibility, though one not inconsistent with the preceding contention, involves the dual-phase history of Negro protest in the South during the 1960's. In the early years of this decade, the focus of militant civil rights activity-boycotts, freedom rides, sit-ins, and other actions by SCLC, SNCC, and CORE-was upon segregation and discrimination in Southern settings. In a number of instances, racial violence followed in the wake of tensions generated in a community by these protests. ${ }^{16}$ Since the location of civil rights activity in the early 1960's was, to a disproportionate extent, in communities with sizable Negro populations (Birmingham, Montgomery, Jacksonville, and Savannah are some cities which witnessed demonstrations and experienced disorders in subsequent days), the noted decrease in disorderproneness among large Negro population centers, relative to smaller communities, could reflect the contraction of traditional civil rights protests in the South in recent years.

Both of these arguments suggest that the distribution of Negro uprisings in the South may be converging to the pattern which has prevailed in the non-South throughout the decade. If this assertion is correct, then the 1968 disorders in this region should conform more closely to the relationship between Negro population size and outbreaks of racial violence which has been characteristic of the non-South than to the earlier relation between these variables in the South. To investigate this possibility, the 1961-67 curve for the non-South was used together with the Negro population figures for Southern cities to compute an expected number of disturbances for each city, contingent upon the non-South relation.

The results are reported in Table 6 . In Column 1 the grouping of disorders which was used in panel B of Table 5 is again presented. In Column 2 the number of disorders predicted for each category from the 1961-67 curve for the non-South is reported. It is evident from a comparison of these two distributions that the non-South relation is eminently more successful in predicting the 1968 disturbances in the South than is the curve constructed from the earlier disorders in this region. Consequently, the contention that the distribution of outbreaks in the South has been converging over time to the pattern which has been

${ }^{16}$ Disorders which could be directly linked to civil rights protests or to other organized activities were deleted from the analysis. In many instances, however, the decision as to whether a disturbance was "spontaneous" or derivative of some earlier protest was arbitrary. 
Table 6. Predicted and Actual Disprders for South in 1968. from Non-South Curve for 1961-67. by Negro Population size. ${ }^{a}$

\begin{tabular}{l|ccc}
\hline $\begin{array}{l}\text { Negro } \\
\text { popul. } \\
\text { size }\end{array}$ & (1) & $\begin{array}{c}(2) \\
\text { Actual }\end{array}$ & $\begin{array}{c}\text { Predicted } \\
\text { (cities) }\end{array}$ \\
\hline 1 & 3 & 4.4 & 5 \\
2 & 5 & 2.7 & 5 \\
3 & 5 & 3.5 & 8 \\
4 & 6 & 5.2 & 14 \\
5 & 11 & 10.2 & 33 \\
6 & 12 & 15.9 & 107 \\
Total & 42 & 41.9 & 172 \\
\hline
\end{tabular}

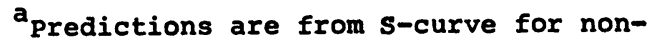
south, 1961-67. See footnote (a) in Table 5 for parameter values.

$b_{\text {Total }}$ predicted disorders were standardized to sum to empirical total for South in 1968.

characteristic of the non-South is supported by the analysis. Whether for the reasons cited above, or for others, it appears that Negroes in this region have begun to respond to the frustrations associated with being black in much the same manner that Northern Negroes have throughout the 1960's.

\section{v. CONCLUSIONS}

The question of the adequacy of an explanation has rarely been treated in a systematic fashion. In this paper, this matter was addressed with respect to a recently proposed explanation for the distribution of racial disorders in the 1960's. It has been argued (Spilerman, 1970b) that these incidents were primarily responses to deprivations which are felt by Negroes living in all cities in the country. A number of factors were cited in that study as having operated to override the impact of community variations in the material situation of Negroes as a potential source of unrest. Among these are the reliance by Negroes upon the federal government to promote equality, the emergence of a racial identity which transcends community boundaries, and the wide availability of television. Each of these factors- a potential source of disappointment to $\mathrm{Ne}$ groes in all cities, a common cognitive structure for interpreting events in racial terms, and a news medium structured by network programming-serves to promote geographic uniformity in the impact of frustrating stimuli.

The findings reported in this paper both qualify and strengthen the above contention. The explanation is qualified in that, while originally proposed as applicable to disorders in all sections of the country, upon closer inspection it has been found to be appropriate mainly to outbreaks in the non-South. With respect to this region, however, the contention is bolstered by evidence from three separate analyses which suggest that practically all the variation in number of disorders that can be explained using community level variables may be already accounted for by Negro population size. In the non-South, then, Negroes appear to have been responding as a cohesive ethnic unit, not as residents of 501 autonomous communities provoked by their parochial frustrations.

For the South, the results are less straightforward. Two political structure variables were found to be related to racial turmoil and, by one interpretation, they suggest that disorders were more likely where municipal officials lacked the structural support to make unpopular decisions (such as to compromise with civil rights protestors). Over time, however, the distribution of disorders among Southern cities has converged to the pattern which has been prevalent in the non-South, suggesting that black consciousness is beginning to pervade even small Southern communities.

Several additional points warrant comment in order to place these findings in proper perspective. First, this investigation has been restricted to ascertaining the causes of rioting as they relate to the locations of the disorders. The problem we have considered is whether particular institutional arrangements make for disorder-proneness. It is not possible to explain the over-time variation in number of outbreaks from these results or, in particular, to account for their sudden upsurge in the mid-1960's. Hypotheses have been advanced on this matter, the most common being that the gap between expectations and reality has increased for 
the Negro during the Kennedy and Johnson presidencies (National Advisory Commission, 1968:106-110; Fogelson, 1968:3839). The findings reported in this study, however, neither support nor contradict this or any other explanation of the over-time change. They are relevant to explanations of the temporal variation only in one way. By showing the national character to the outbreaks, they suggest that it will not be possible to choose among alternative explanations which are consistent with the trend in the national rate during the 1960's.

A second qualification concerns our ability to generalize from these conclusions to future disorders. It is not necessarily the case that the location of racial violence in subsequent years, if it should occur, will follow the relationships reported in this study. For that matter, trends are at work which may make these results idiosyncratic of the 1960's. Negro mayors have recently been elected in several cities and more are likely to follow. Militant nationalist groups, possibly prepared to employ violent means, ${ }^{17}$ have become established in other cities. At the same time, accompanying the election of Richard Nixon, the federal government has become less articulate as a proponent of Negro rights. ${ }^{18}$ In combination, these trends may mean that explanations of the location of future disorders will require a consideration of community characteristics. Correspondingly, there is evidence that community conditions were related to the location of racial violence in the first half of this century (Lieberson and Silverman, 1965). This is not at all surprising since the factors enumerated in the preceding discussion as having induced geographic uniformity onto the pattern of Negro aggression during the

17 At this writing, December 1969, the Chicago and Los Angeles police have just raided the Black Panthers' headquarters in the two cities. The location of militant black groups would also be related to the distribution of future disturbances if police instigated actions against them provoke community uprisings.

18 Following expectational theory, Bowen and Masotti (1968:24-25) suggest that the racial disorders of the 1960's may have been expressions of frustration in a milieu of hope and optimism. Negro aggression during a mood of futility and despair may take a very different form, possibly one of organized guerrilla attacks. 1960's were hardly present before World War II.

In addition to these qualifications on generalizing from the findings, a final comment on the concept of randomness seems necessary. What is intended by the claim that the results for the non-South are consistent with ${ }^{19}$ a complete explanation of disorderproneness in that additional variables may be unable to reduce the unexplained variation? After all, at least theoretically, variables could be introduced to account for the probability of a car accident at a particular street corner in a ghetto, and even for the strolling behavior of every individual in the city.

As used in this study, randomness is tied to the level of observation. The findings reported here therefore apply only to community as the unit of investigation. No inference is intended with respect to observations at a different conceptual level, such as using the individual person as the analytic unit and predicting the occurrence of disturbances from the interactions among individuals. Following Nagel (1961:331-333), we therefore distinguish between relative chance and absolute chance. Under absolute chance, random behavior is held to be "uncaused." Under relative chance, the random behavior observed at one level may have causal antecedents at a different conceptual level. For our purpose, the weaker assumption of relative chance is sufficient. Nevertheless, with regard to theorizing on the relationship between community organization and disorder-proneness, reductionist explanations have little utility.

19 This phrase is intended to convey the fact that it is not possible to prove an explanation by empirical examination. The burden of this paper has been an attempt to disconfirm a thesis by subjecting it to several tests. What can be said is that, because these attempts failed, the explanation is now more credible. For a discussion on the logic of theory verification see Stinchcombe (1968:15-56).

\section{REFERENCES}

Aiken, Michael and Robert Alford

1970 "Community structure and innovation: The case of urban renewal." American Blau, Peter Sociological Review 35 (August):650-665.

1970 "A formal theory of differentiation in 
organizations." American Sociological Review 35 (April):201-218.

Blau, Peter and W. Richard Scott

1962 Formal Organizations. San Francisco: Chandler.

Bowen, Don R. and Louis H. Masotti

1968 "Civil violence: A theoretical overview." In Louis H. Masotti and Don R. Bowen (eds.), Riots and Rebellion. Beverly Hills: Sage.

Brink, William and Louis Harris

1967 Black and White. New York: Simon and Schuster.

Coleman, James S.

1964 Introduction to Mathematical Sociology. New York: Free Press.

Congressional Quarterly Service

1967 Urban Problems and Civil Disorder. Special Report No. 36 (September):3-6.

Crain, Robert L., Elihu Katz and Donald B. Rosenthal

1969 The Politics of Community Conflict: The Fluoridation Decision. Indianapolis: BobbsMerrill Co.

Downes, Bryan T.

1968 "Social and political characteristics of riot cities: A comparative study." Social Science Quarterly 49 (December):504-520.

Feller, William

1957 An Introduction to Probability Theory and Its Applications. Vol. 1. New York: Wiley.

Fogelson, Robert M.

1968 "Violence as protest." Proceedings of the American Academy of Political Science 29 (No. 1):25-41.

Goulden, Cyril $\mathrm{H}$.

1952 Methods of Statistical Analysis. New York: Wiley.

Lemberg Center for the Study of Violence

1968a Compilation of the 1967 Disorders. Brandeis University. Unpublished.

1968b Riot Data Review. Numbers 1-3. Brandeis University. Mimeographed.

Lieberson, Stanley and Arnold R. Silverman

1965 "The precipitants and underlying conditions of race riots." American Sociological Review 30 (December):887-898.

Lotka, Alfred J.

1956 Elements of Mathematical Biology. New York: Dover.
Maloney, John C.

No "A study of riot-proneness in American

Date cities." Urban Journalism Center, Northwestern University. Unpublished ms.

Matthews, Donald R. and James W. Prothro

1966 Negroes and the New Southern Politics. New York: Harcourt, Brace and World.

Municipal Yearbook

1967 Chicago: International City Managers' Association.

Nagel, Ernest

1961 The Structure of Science. New York: Harcourt, Brace and World.

National Advisory Commission on Civil Disorders

1968 A Report. Washington: Government Printing Office.

Planck, Max

1936 The Philosophy of Physics. New York: W. W. Norton.

Smelser, Neil J.

1963 Theory of Collective Behavior. New York: Free Press.

Spilerman, Seymour

1970a "Comment on Wanderer's article on riot severity and its correlates." American Journal of Sociology 75 (January):556560.

1970b "The causes of racial disturbances: A comparison of alternative explanations." American Sociological Review 35 (August) :627-649.

Stinchcombe, Arthur

1968 Constructing Social Theories. New York: Harcourt, Brace and World.

U.S. Bureau of the Census

19631960 Census of Population. Vol. 1, Characteristics of the Population. Washington: Government Printing Office.

Vander Zanden, James W.

1966 American Minority Relations. New York: Roland Press.

White, John G.

1968 "Riots and theory building." Pp. 157-168 in Louis H. Masotti and Don R. Bowen (eds.), Riots and Rebellion. Beverly Hills: Sage.

Wisconsin-University of Wisconsin Computing Center

1966 Users' Manual. Vol. 4, Rev. B. Madison, Wisconsin. 